\title{
Fisonomía múltiple de un autorretrato cervantino
}

\author{
Multiple physiognomy of a Cervantine \\ self-portrait
}

IGNACIO ARELLANO TORRES

Hispanic Languages and Literature Department Stony Brook University

Franklyn Melville Library, Office N3023

Stony Brook, New York 11794. EE.UU.

ignacio.arellano@stonybrook.edu

Orcid ID 0000-0001-6078-6875

Resumen: Existe en las Novelas Ejemplares una resonancia dual marcada ya desde el título que nos remite tanto al género del exemplum como al de la novella. La tensión entre el entretenimiento y el aprovechamiento de lo leído queda reflejada en el prólogo a través del retrato que el autor hace de sí mismo. En relación con esta múltiple naturaleza, se analizan en este trabajo las posibilidades interpretativas del autorretrato cervantino en los planos poético y estético, ético y autobiográfico. La forma burlesca y el tono jocoso de la descripción convive con matices que remiten a las profundas preocupaciones de un autor ya anciano que enfrenta la imagen decrépita de la senectud con el entusiasmo jovial de quien se sabe camino de la fama.

Palabras clave: Etopeya. Prosopografía. Écfrasis. Aspecto. Retrato. Autobiografía.
RECIBIDO: 16 DE ENERO DE 2017 ACEPTADO: 20 DE ENERO DE 2017

\begin{abstract}
There exists in the Novelas Ejemplares a dual resonance marked by a title that talks about both the genre of the exemplum and that of the novella. The tension between entertainment and learning remains reflected in the prologue thanks to the portrait of the author made by himself. In relation with this multiple nature, I analyze in this article the interpretative possibilities of the Cervantine self-portrait in the poetic and aesthetic planes, but also in those of the ethics and the autobiography. The burlesque form, the jocular tone of the description, coexists with shades that talk about the deep worries of an already elderly author, who counterposes the decrepit image of the old age, with the cheerful enthusiasm of the one who knows himself on the way to everlasting fame.
\end{abstract}

Keywords: Ethopoeia. Prosopography. Ecphrasis. Aspect. Portrait. Autobiography. 
E

xplica Covarrubias en su Tesoro de la lengua que aspecto se refiere al 'semblante' y a la 'vista'. Si se acude a la acepción de semblante, lo define como "el modo en que mostramos en el rostro alegría o tristeza, saña, temor o otro cualquier accidente [...] porque semeja en el rostro lo que uno tiene en el corazón". Es decir, se establece la correspondencia de lo interno (el corazón), con lo externo (el rostro), acorde a las circunstancias dadas, sean de tristeza, temor, etc. Las mudanzas del rostro son fruto de las pasiones del alma y las condiciones del ánimo. Si acudimos a la voz retrato, remite a "la figura contrahecha de alguna persona principal de cuenta, cuya efigie y semejanza es justo que quede por memoria a los siglos venideros”. Ahora se nos introduce en una temporalidad que va más allá de la correspondencia con un concreto momento y un concreto reflejo de pasiones o emociones. El retrato tiene como objetivo mostrar a la posteridad la excelencia del sujeto. Tratándose de Cervantes no podemos sino considerar la principalidad como resultado de la confluencia de las virtudes morales con su desempeño como literato. No se trataría entonces de la expresión de lo momentáneo, sino de lo eterno. Los preceptos humanistas antropocéntricos ya están definidos de un modo que supera la tradicional proyección teleológica del alma. Ahora lo corpóreo es un elemento tenido en cuenta, la principalidad y la dignidad del hombre pueden ser, como demuestra Cervantes, proyectadas a través de narrativas con un sólido valor de imagen.

Aunque la representación de aspectos y retratos son dibujos de distintos elementos del sujeto, el prólogo de las Novelas Ejemplares es un ejercicio ecfrático que aúna ambos enfoques. Este es el muy conocido pasaje que conviene traer a la memoria desde el citado prólogo:

Este que veis aquí, de rostro aguileño, de cabello castaño, frente lisa y desembarazada, de alegres ojos y de nariz corva, aunque bien proporcionada; las barbas de plata, que no ha veinte años que fueron de oro, los bigotes grandes, la boca pequeña, los dientes ni menudos ni crecidos, porque no tiene sino seis, y ésos mal acondicionados y peor puestos, porque no tienen correspondencia los unos con los otros; el cuerpo entre dos extremos, ni grande, ni pequeño, la color viva, antes blanca que morena, algo cargado de espaldas, y no muy ligero de pies. Este digo, que es el rostro del autor de La Galatea y de Don Quijote de la Mancha, y del que hizo el Viaje del Parnaso a imitación del de César Caporal Perusino, y otras obras que andan por ahí descarriadas y, quizá, sin el nombre 
de su dueño. Llámase comúnmente Miguel de Cervantes Saavedra. Fue soldado muchos años, y cinco y medio cautivo, donde aprendió a tener paciencia en las adversidades. Perdió en la batalla naval de Lepanto la mano izquierda de un arcabuzazo, herida que, aunque parece fea, él la tiene por hermosa, por haberla cobrado en la más memorable y alta ocasión que vieron los pasados siglos, ni esperan ver los venideros, militando debajo de las vencedoras banderas del hijo del rayo de la guerra, Carlo Quinto, de felice memoria.

$\mathrm{Y}$ cuando a la deste amigo de quien me quejo, no ocurrieran otras cosas de las dichas que decir de mí, yo me levantara a mí mismo dos docenas de testimonios, y se los dijera en secreto, con que estendiera mi nombre y acreditara mi ingenio. Porque pensar que dicen puntualmente la verdad los tales elogios es disparate, por no tener punto preciso ni determinado las alabanzas ni los vituperios.

En fin, pues ya esta ocasión se pasó, y yo he quedado en blanco y sin figura, será forzoso valerme por mi pico, que, aunque tartamudo, no lo será para decir verdades, que, dichas por señas, suelen ser entendidas.

En la descripción de su propia figura se puede rastrear la correspondencia necesaria de alma (eterna y esencial, aunque motor de pasiones) con el cuerpo, pero también analizar la permeabilidad del rostro y el cuerpo a los sentimientos y las circunstancias (pasajeras y accidentales). En términos narrativos esta voluntad se articula a través de un retrato híbrido en cuanto a su origen literario. Señala Salgado, siguiendo el estudio de Michalski, que "al combinar la estructura verista del idealizado retrato retórico con la deformación naturalista casi, del fisonómico, Cervantes buscaba un mayor realismo" (212). Pero Cervantes introduce en el género la novedad de combinar dos tradiciones distintas, abriendo enormes posibilidades en cuanto al tratamiento de los personajes, enriqueciendo su universo narrativo con texturas ricas en su dimensión psicológica; anunciando, como señala esta autora, las posteriores producciones pictóricas velazqueñas.

Cervantes advierte que "blanco y sin figura, será forzoso valerme por mi pico". Asume la labor de autorretratarse para la posteridad dado que ya "pasó la ocasión" de que un "amigo" llevase a cabo esa labor siguiendo "el uso y la costumbre, grabarme y esculpirme en la primera hoja de este libro". Es el pico de Cervantes el que habla y cincela su propia escultura, pues "Cervantes transforma este «Prólogo» y su autorretrato en un ejercicio ficcional al construir 
otra vez un alter ego para poner a su cuenta aquello de lo que a él no le conviene hacerse cargo" (Stoopen 78). Cumple resaltar que la voz metafórica pico remite al instrumento animal cuya función es la de picar, que significa en el Siglo de Oro 'herir de punta', hacer una incisión hiriente, utilizar una herramienta para grabar una marca, en este caso en la primera hoja del libro. Los términos usados refuerzan el valor plástico y material de la evocación conceptual sugerida. La herramienta de la que hace uso Cervantes es la palabra escrita (a través de su propio pico, su palabra), en una descripción que, si le fuera ajena, bien pudiera ser hiriente, pero que siendo obra del ingenioso autor esconde una gran carga de autoalabanza como se mostrará al analizar la descripción.

$\mathrm{El}$ autorretrato establece una división entre rostro y cuerpo. Como explica Altuna, el rostro es "la parte más expuesta, más pública, más desnuda, más expresiva" (14), y por ello merece una atención especial. La descriptio, siguiendo el esquema retórico del retrato, muestra que Cervantes no es ajeno a esta convención. En el autorretrato cervantino se asume el orden convencional, el patrón clásico de la effictio. Podemos leer en el autorretrato toda una declaración estética: respeto a la tradición y a las convenciones narrativas, pero al servicio del genio innovador y moderno del autor barroco donde la importancia de lo visual y de la imagen aportan relieve a la proyección conceptual literaria.

Las descripciones separan cuerpo y rostro, o bien, como vemos en la descripción corporal de Sancho Panza en el Quijote, recogida en la pintura de los cartapacios, se centran en uno de los dos aspectos: "la barriga grande, el talle corto y las zancas largas y por esto se le debió de poner nombre de Panza y de Zancas" (I, 9). Tenemos un ejemplo de la estructura de la descripción también en la figura de Maritornes:

Ancha de cara, llana de cogote, de nariz roma, del un ojo tuerta y del otro no muy sana. Verdad es que la gallardía del cuerpo suplía las demás faltas: no tenía siete palmos de los pies a la cabeza, y las espaldas, que algún tanto le cargaban, la hacían mirar al suelo más de lo que ella quisiera. (I, 16)

No significa esto que siempre guarde la literatura áurea el orden canónico, ya que hay ejemplos de lo contrario, como señala Arellano Ayuso refiriéndose al retrato de Isdaura (soneto "Un tenedor con medias y zapatos", de Quevedo): "El principio de selección caricaturesca exime al poeta de seguir el orden tra- 
dicional retórico de arriba abajo y observa los rasgos más aptos para producir el efecto ridículo perseguido, en un esquema que podría ser considerado de enumeración caótica" (Arellano Ayuso 262).

Volviendo al prólogo cervantino, a pesar de ser teóricamente un retrato -el propio autor lo describe como tal: "pues le diera mi retrato el famoso Juan de Jáurigui”-, y que por ello debiera remitirnos a una temporalidad de larga duración y al reflejo de las virtudes eternas del individuo (aquellas que le hacen digno de pasar a la posteridad, superando la muerte), la referencia a las barbas que señalan el paso del tiempo lo acerca a una representación física más cercana al universo de las circunstancias accidentales y pasajeras, más cercana a la representación del tiempo, no a su superación. Estaría entonces más cerca del mundo del aspecto. La descripción física conlleva una carga emocional en la que vemos la autoconciencia de la vejez, el sentido especular del autorretrato, en él ve Cervantes su propio semblante. No es esta, en apariencia, la digna vejez eternizada en los bustos de los prohombres quienes -no por casualidad-siempre tienen la boca cerrada. $\mathrm{Al}$ ser el propio autor quien rebaja el porte del ilustre retratado, se puede considerar el pasaje como un autorretrato jocoso, que corresponde en el Siglo de Oro a todo un género poético ejercido por multitud de escritores como Lope, Góngora, Polo de Medina, Calderón, Catalina Clara Ramírez de Guzmán y otros. Baste recordar el poema gongorino "Hanme dicho, hermanas", dada la coincidencia con el autorretrato cervantino de la voz "aguileña" y el hecho de que, como en el caso del prólogo de las Novelas Ejemplares, se hace mención explícita a lo pictórico: no es pintado sino escrito:

Hanme dicho, hermanas, que tenéis cosquillas de ver al que hizo a Hermana Marica; por que no mováis, él mismo os envía de su misma mano su persona misma, digo, su aguileña filomocosía ya que no pintada, al menos, escrita. 
La escritura, a diferencia de los soportes plásticos, es definida en su propia complejidad conceptual abriendo el abanico de las posibilidades interpretativas: "La abstracción-conceptualización que caracteriza la lengua, si bien limita los efectos sensibles, la capacita, por el contrario, para referirse y dar cuenta de muchos más aspectos del ser humano que de lo que podían hacer los materiales físicos" (Iriarte 54).

El particular cervantino es un acto consciente de resiliencia. A través de lo prosopográfico nos habla de lo etopéyico, introduciéndonos en el universo psicológico de un hombre que necesita hacer uso de lo jocoso para superar las dinámicas problemáticas propias de la edad, cosa que por el contrario no consiguen aquellas damas aludidas por las sátiras áureas, entre otras las quevedianas, que son objeto de burla precisamente por ser incapaces de enfrentarse al paso del tiempo. Cervantes abre la boca, literaria y literalmente, mostrando su dentadura al lector. Siendo el retrato una justificación de su valía, un alegato de su derecho a inscribirse en los libros de la fama dada su calidad como literato, bien le pudiera interesar al lector la catadura del mismo ya que no hay que olvidar que se trata de un prólogo, antesala de lo que el lector enfrenta. Evocando prácticas propias del universo animal, donde la dentadura revela la edad y la condición de las caballerías, el autorretrato jocoso cervantino muestra al lector la calidad del mismo invirtiendo a través de lo satírico el significado adscrito al significante de lo decrépito y lo viejo. Los degradados dientes del autor, marcados por la edad, son símbolo de una insigne trayectoria de amplio bagaje literario. Pero vayamos por partes como indican los cánones descriptivos.

Empieza Cervantes por referirse a su "rostro aguileño". Ya se ha comentado que el rostro en un principio remite al semblante donde se puede leer el corazón. El adjetivo que usa Cervantes para acompañar al rostro es aguileño. Covarrubias nos habla de tres aspectos diferentes. El primer elemento al que se refiere es la longitud del rostro, 'un poco largo'. El segundo elemento que nos explica es relativo a la nariz, 'con forma de pico de águila'. Estos dos primeros tienen una connotación descriptiva de fuerte componente visual. El tercer elemento que recoge Covarrubias es que, 'suelen ser los tales ingeniosos y animosos'. Introduce, pues, Cervantes, un retrato psicológico que va más allá de lo que aparece superficialmente, al hacer una implícita defensa de su ingenio que concuerda perfectamente con el tono y el registro satírico del retrato físico tras el cual, aunque aparentemente no se muestre muy agraciado, se esconden $-y$ se revelan- muchas gracias. A las damas objeto de burla 
anteriormente referidas, la sátira las rebaja, pero cuando se trata de autorretratos, la sátira -pseudosátira- ensalza. En palabras de Salgado, "es por eso la sátira, uno de cuyos fines es ridiculizar vicios y vanidades, lo que proporcionaría al escritor barroco el vehículo idóneo para autorretratarse, soslayando así cualquier sospecha de autoengrandecimiento" (214).

Continúa la descripción con "los cabellos castaños", que comenta Blecua: "Lo de los cabellos castaños es sospechoso en un anciano con las barbas de plata, y parece claro indicio de que el autor se refería, como en estos últimos rasgos físicos e intelectuales, a la descriptio de un Cervantes en su perfecta edad y varón perfecto" (40). La lectura simbólica parece la más plausible, pero vale la pena atender a la única acepción de castaño recogida en el Tesoro de Covarrubias: "Castaño: color en los caballos y mulas; y divídese en castaño escuro y castaño claro, por tener la color de la cáscara de la castaña”. En una lectura quizá improbable, pero no del todo imposible, Cervantes estaría introduciendo un elemento de auto animalización en el retrato, subrayando a través de lo jocoso el hecho de su madurez intelectual y moral. Sigue la mención a la "frente lisa y desembarazada", espacio fisionómico donde "trae el hombre escrito mucho de lo que tiene en el ánimo: la serena y rasa significa quietud, alegría y clemencia" (Covarrubias). La frente de Cervantes es lisa y, siempre según el diccionario, "metafóricamente llamamos cosa lisa a la que es llana y sin tropiezo ni cautela. Hombre liso, hombre de verdad". La voz lisa, se relaciona directamente con la voz rasa que sirve para definir la naturaleza del individuo (quieto, alegre y clemente) con lo que a su buen ánimo e ingenio se le suman ahora la quietud, la alegría y la clemencia, virtudes que empiezan entonces a justificar la voz de retrato y la aspiración del autor de grabar una escultura que pueda pasar a la posteridad, trascendiendo la temporalidad humana. También se puede entender la frente lisa en clave metonímica como muestra de un hombre liso, un hombre de verdad, habiendo entonces de sumarle a Cervantes otra virtud. Refuerza esta imagen el adjetivo desembarazada, es decir libre de estropiezos, lisa, rasa. En cuanto a los ojos, describe los suyos como "alegres". Según Covarrubias, los ojos son, "la parte más preciosa del cuerpo, pues por ellos tenemos noticia de tantas cosas. Ellos son las ventanas adonde el alma suele asomarse dándonos indicios de sus afectos y pasiones de amor y odio, Son los mensajeros del corazón y los parleros ocultos de nuestros pechos".

Otra vez el corazón, las pasiones, no las virtudes, otra vez lo temporal y pasajero, lo accidental, el aspecto, el semblante. Pero esta definición señala 
un dato significativo. Rostro y cuerpo, a los cuales nos habíamos referido como elementos separados, se integran gracias a la posibilidad de trascender la externalidad para ver en los ojos del escritor la interioridad del mismo. Se aúnan entonces la temporalidad limitada, el mundo de las pasiones, con la eternidad del mundo de las virtudes, y a través de esta proyección del mundo de las virtudes se inscribe el autorretrato en el ámbito de la ética. Retrato que aun con sus detalles burlescos e hirientes, empieza a configurarse como una auto-hagiografía. Pareciera que Cervantes, preocupado por sus barbas ya canas, estuviera escribiendo su honroso epitafio. Estaría prologando una serie de novelas, sí, pero ejemplares.

De lo oculto a lo que sobresale, a lo visible, a la nariz, rasgo el más saliente, habitual protagonista de caricaturas como el famoso soneto quevediano "Érase un hombre a una nariz pegado". La nariz corva de Cervantes -que había anticipado la referencia a su rostro aguileño- supone un rasgo redundante, quizá para subrayar la función simbólica de este apéndice. Cervantes resalta su buena proporción para alejarse de posibles malentendidos, pues el tamaño de la nariz en el Siglo de Oro era -además de su inclinación a lo grotesco- un tópico recurrente asociado a los judíos. En su texto trata de ponderar otro simbolismo tópico de la nariz, su asociación con la capacidad de ingenio, recogido entre otros muchos por Gracián en el Criticón, donde la llama "facción de la prudencia" y "señuelo de la sagacidad" (II, 200). Menciona Covarrubias la existencia de toda una teoría de las narices en la que no se extiende por no alargarse. Más allá de la consideración que de los tratados fisionómicos se tuviera, los autores hacen uso frecuente de los simbolismos asociados a los rasgos físicos para trazar sus obras. Aquí puede recordarse la diferencia con la nariz roma de la anteriormente referida Maritornes, que puede funcionar como negativo del autorretrato cervantino. Según el tratado de Ambrosio de Bondía, estudiado por Laplana, "la nariz que se dice chata es señal de lujuria" (151). Si nos fiásemos de la coherencia del físico cervantino con su -según el autor- virtuoso mundo interior, no habría siquiera que acudir a los tratados de fisionomía para percibir que la nariz corva vuelve a mostrar la quietud y el buen ánimo del personaje (se trata de una nariz "bien proporcionada"). Añádase lo que el propio tratado de Bondía dice: "nariz larga, al extremo corva, puntiaguda, que se dice aguileña, es señal de magnánimos, generosos y reales" (Laplana 151).

Miremos ahora otro rasgo ya aludido: "Las barbas de plata, que no ha veinte años que fueron de oro". Es curioso apuntar que, en cuanto a la calidad de los metales, plata es "metal precioso después del oro" (Covarrubias), la 
misma correlación que en paso del tiempo, la vejez tras la juventud. Indica el mismo diccionario siguiendo las etimologías de San Isidoro, que "barba est decorum signum, virilitatium indicium". El decoroso autor en su madurez introduce el elemento retrospectivo, estableciendo una atalaya desde la cual juzgar su pasado y ofrecer al lector una historia, la suya propia. Eso sí, como acostumbra Cervantes en el autorretrato, no se abstiene de introducir el aspecto honroso junto al burlón a través del uso de la voz en plural, que puede evocar cierta animalización burlesca del sujeto representado, ya que las barbas -en plural- son algo que pertenece al ganado: "Barbam hominum, barbas pecudum dicimus" (Covarrubias).

Los "bigotes grandes" forman parte de las barbas. Con ellos se profundiza en este sentido burlesco que, de no ser un autorretrato, sería hiriente. Del francés bigot, "supersticioso, e hipócrita: y en cierta manera lo son los que traen los bigotes muy largos, porque pretenden parecer valientes y espantabobos, como los que para dar a entender eran grandes filósofos se dejaban crecer la barba" (Covarrubias). El rasgo cervantino parece en realidad una falsa modestia. La descripción del rostro finaliza con "la boca pequeña, los dientes seis, y ésos mal acondicionados y peor puestos, porque no tienen correspondencia los unos con los otros". La boca pequeña pudiera representar otra vez esa falsa modestia que sirve al autor para establecer el juego burlesco. Parece significar el humilde autor que tiene poco que decir, ya que tiene la boca pequeña; en la lógica del autorretrato deberemos entender lo contrario, que tiene el autor muchas cosas de valor dichas, algunas de las cuales resume en el capítulo IV del Viaje del Parnaso, en una especie de "retrato profesional, o curriculum de un «poetón ya viejo»", que "es complemento de su retrato físico en el Prólogo de las Novelas Ejemplares [...], canónico ejemplo de retrato literario" (Arredondo 169). Los dientes son el elemento que más claramente transforma el retrato en un pasaje caricaturesco y burlesco. Son la herramienta de la que se sirve Cervantes para introducir un juego con la eternidad y la fugacidad del tiempo, para introducir un juego con la esencialidad y la accidentalidad. En el tratamiento del aspecto corpóreo y del retrato, el pasaje nos remite a los problemas ontológicos de la filosofía clásica, abogando Cervantes por una narrativa permeable a elementos tanto esenciales como accidentales.

En cuanto al cuerpo, está "entre dos extremos, ni grande, ni pequeño, la color viva, antes blanca que morena, algo cargado de espaldas y no muy ligero de pies". Ni grande ni pequeño. En el justo medio. Como corresponde 
al virtuoso siguiendo la tradición aristotélica en cuanto al equilibrio de los humores, como ya señaló Blecua (40). De la voz color observamos que Covarrubias, como hace en lo referente a la "nariz", no entra en explicar las consideraciones del vulgo, pero apunta que el blanco significa 'castidad, limpieza, alegría'. "Cargado de espaldas y no muy ligero de pies" se puede contraponer con el retrato de Maritornes, quien también tenía las espaldas cargadas en su gallardo cuerpo, sirviendo estos dos ejemplos como muestra de las diversas posibilidades del lenguaje satírico.

Termina con la referencia a la manquedad, "herida que, aunque parece fea, él la tiene por hermosa, por haberla cobrado en la más memorable y alta ocasión que vieron los pasados siglos ni esperan ver los venideros”. Se trata en realidad de un compendio de todas las características del autorretrato. Enfrenta fealdad y hermosura. Si la supuesta fealdad se debe por haber sufrido una herida en un episodio concreto, localizado en el tiempo y en el espacio, la hermosura se debe a que este episodio es partícipe de la eternidad, es memorable, y merece pasar a la posteridad por ser efecto de virtud. Al escribir sobre su mano, el autorretrato de Cervantes integra en realidad toda una autobiografía, un ejercicio de historia, "síntesis de su proyecto de pasar a la historia literaria trazando desde sus obras iniciales a las últimas la primera historia crítica de lo que llamaban poesía" (Blecua 39).

En conclusión, el retrato sirve a Cervantes para justificar su derecho a pasar a la posteridad, no solo por su labor literaria sino por su participación en un escenario de virtud como la batalla de Lepanto, aunándose la poética con la historia. Esto es, el autorretrato puede ser entendido como un pasaje que, a través de una escritura evocadora de lo visual y de una narrativa de naturaleza híbrida (retrato retórico y autorretrato jocoso), proyecta su simbolismo en el ámbito de lo ético, lo ontológico, lo poético, lo estético, lo histórico y lo autobiográfico. El autor construye una imagen de sí mismo que, más allá de ser certera o no, permita una lectura rica en matices y significados, todos ellos enfocados a colocar su busto en el pódium de la fama.

\section{OBRAS CITADAS}

Altuna, Belén. Una historia moral del rostro. Valencia: Pre-textos, 2010.

Arellano Ayuso, Ignacio. Poesía satírico-burlesca de Quevedo: estudio y anotación filológica de los sonetos. Madrid: Iberoamericana, 2003.

Arredondo, M. ${ }^{a}$ Soledad. "El pincel y la pluma: sobre retratos, paisajes y bo- 
degones en la literatura del Siglo de Oro". Anales de Historia del Arte. Vol. extraordinario (2008): 151-208.

Blecua, Alberto. "Cervantes historiador de la literatura". Cervantes, El "Quijote” y Barcelona. Coords. Carme Riera y Guillermo Serés. Barcelona: Fundación La Caixa, 2007. 37-47.

Cervantes, Miguel de. Novelas Ejemplares. Ed. Frances Luttikhuizen. Barcelona: Planeta, 1994.

Cervantes, Miguel de. Don Quijote de la Mancha. Ed. Francisco Rico. Barcelona: Instituto Cervantes/Crítica, 1998.

Covarrubias Orozco, Sebastián de. Tesoro de la lengua castellana o española. Eds. Ignacio Arellano y Rafael Zafra. Madrid: Iberoamericana, 2006.

Góngora, Luis de. Romances. Ed. Antonio Carreira. Barcelona: Quaderns Crema, 1998.

Gracián, Baltasar. El Criticón. Ed. Miguel Romera-Navarro. Philadelphia: University of Pennsylvania UP, 1938.

Iriarte López, Margarita. El retrato literario. Pamplona: Eunsa, 2004.

Laplana Gil, José Enrique. "Un tratado de fisiognomía de 1650”. Scriptura 11 (1996): 141-54.

Salgado, María Antonia. "De lo jocoso a lo joco-serio, el autorretrato literario en los Siglos de Oro y la Ilustración". Actas del XII Congreso de la Asociación Internacional de Hispanistas. Vol. 3. Birmingham: University of Birmingham, 1998. 212-20.

Stoopen, María. "De retratos y autorretratos: «prosopografía y etopeya» en el «Prólogo» y en las Novelas ejemplares". Las Novelas Ejemplares: texto y contexto (1613-2013). Eds. Aurelio González y Nieves Rodríguez Valle. México: Colegio de México, 2015. 75-84. 